\title{
Hypothetical glycerol pathways of newly isolated strains capable of 1,3-propanediol production
}

\author{
Katarzyna Leja ${ }^{凶}$, Dorota Samul, Agnieszka Drożdżyńska, Kamila Myszka, Wojciech Juzwa, \\ Joanna Pawlicka and Katarzyna Czaczyk
}

Department of Biotechnology and Food Microbiology, Poznan University of Life Sciences, Poznań, Poland

\begin{abstract}
Study presented here demonstrates the ability of three newly isolated strains, obtained from environmental probes (manure, bottom sediment, and food waste) and identified as Clostridium bifermentans, Clostridium butyricum, and Hafnia alvei, to synthesize 1,3-propanediol (1,3PD), organic acids (such as lactic, acetic, fumaric, succinic, and butyric acids), and ethanol from glycerol. The production of 1,3-PD as well as the glycerol pathways in C. bifermentans and $H$. alvei cells have not been investigated and described yet by others. Moreover, there is no data in the available literature on the products of glycerol utilization by $\mathrm{H}$. alvei and there is only some incoherent data (mainly from the first half of the twentieth century) about the ability of $C$. bifermentans to carry out glycerol degradation. Additionally, this study presents complete hypothetical glycerol pathways and the basic fermentation kinetic parameters (such as yield and productivity) for both strains as well as for the newly isolated C. butyricum strain.
\end{abstract}

Key words: Clostridium bifermentans, Clostridium butyricum, Hafnia alvei, 1,3-propanediol

Received: 06 March, 2014; revised: 28 May, 2014; accepted: 30 November, 2014; available on-line: 04 December, 2014

\section{INTRODUCTION}

Bacteria from Clostridium species commonly occur in such environmental probes as water, soil, sewage (Nachman et al., 1989), sediment and river sludge (Wang et al., 2003), and animal excrements (Bergey et al., 1984; Leja et al., 2011). H. alvei also exists in the natural environment; i.e. it can be isolated from soil, water, plants, food, intestines of animals and humans (Brenner et al., 2005).

Different types of microorganisms are characterized by specific enzymatic systems, active in the processes of assimilation, fermentation or decomposition. Identification of the capacity of microorganisms to assimilate, ferment and decompose different substrates is crucial for determination of their potential application in specific branches of industry. Bacteria from the genus Clostridium spp. are characterized by an intense fermentation metabolism. The main products of fermentation carried out by Clostridium species are organic acids (acetic, butyric, fumaric, propionic and benzoic) (Bergey et al., 1984; Wu \& Yang, 2003), solvents (butanol, acetone, and ethanol) (Jones \& Woods, 1986), and gases (carbon dioxide, hydrogen, and ammonium) (Khanal et al., 2004;
Levin et al., 2006). However, there is no information in the literature as to which metabolites are produced by Hafnia alvei. On the other hand, some information about the metabolic activity of $C$. bifermentans can be found in the available literature. For example, Brooks and Epps (Brooks \& Epps, 1958) stated that C. bifermentans are able to carry out glycerol, glucose, fructose, maltose, sorbitol, and mannose fermentation. Other scientists, namely Dezfulian and coworkers (Dezfulian et al., 1994)), investigated strains isolated from soil and sewage probes that are able to perform maltose and glucose fermentation. Significantly, these strains were not able to utilize such saccharides as arabinose, cellobiose, lactose, melibiose, raffinose, trehalose, xylose, and glycerol. The presented data about metabolic properties of C. bifermentans strains are not complaisant and, moreover no papers about metabolic pathways in these bacteria have been published lately. It is well-known that bacteria from the genus $C$. butyricum are able to ferment glucose, maltose, fructose, galactose, lactose, sucrose, ramnose, mannose, xylose, arabinose, glycerol, mannitol (Petitdemange et al., 1995). C. butyricum is known as a classical acid producer and it typically ferments glucose to butyrate, acetate, carbon dioxide and molecular hydrogen (Jungermann et al., 1973). When C. butyricum is growing on glycerol, this substrate is oxidized to dihydroxyacetone (DHA) and subsequently phosphorylated to yield DHA-phosphate, or it is dehydrated to 3-hydroxypropionaldehyde (3HPA); the latter compound is then reduced to 1,3-PD (Biebl et al., 1998; Dabrock et al., 1992). Despite the fact that $H$. alvei is described as a strain capable of glycerol fermentation, there is no literature data about its ability for 1,3-PD production. Thus, we decided to investigate and present hypothetical pathways of glycerol in the environmental isolates of C. bifermentans, C. butyricum, and H. alvei.

\section{MATERIALS AND METHODS}

Microorganisms. C. bifermentans KM 371 was isolated from a manure sample (obtained in the Wielkopolska Region, Poland). This strain was identified and precisely characterized in a previous work by Myszka and coworkers (Myszka et al., 2012). C. butyricum DO14 was isolated from a bottom sediment (in the Kujawsko-Pomorskie Region, Poland). This strain was identified in a previous

e-mail: katleja@up.poznan.pl

Abbreviations: 1,3-PD, 1,3-propanodiol; LA, lactic acid; FA, fumaric acid; AA, acetic acid; SA, succinic acid; BA, butyric acid; Et, ethanol 
work by Orczyk and Szymanowska-Powałowska (Orczyk \& Szymanowska-Powałowska, 2012).

H. alvei $\mathrm{AD} 27$ was isolated from food waste.

Stocks of investigated strains are kept at the culture collection of the Department of Biotechnology and Food Microbiology at Poznań University of Life Sciences.

Cultivation medium. C. bifermentans bacteria were cultivated in the modified PY medium (Biebl \& Spröer, 2002) consisting of $(\mathrm{g} / \mathrm{L})$ : BactoPeptone 10 ; yeast extract 10; $\mathrm{CaCl}_{2}, \mathrm{MgSO}_{4} \times 7 \mathrm{H}_{2} \mathrm{O} 0.96 ; \mathrm{K}_{2} \mathrm{HPO}_{4} 2 ; \mathrm{NaHCO}_{3} 20 ; \mathrm{NaCl}$ 4. The medium was supplemented with glycerol $(50 \mathrm{~g} / \mathrm{L})$.

C. butyricum was cultivated in the modified Rich Medium (Himmi et al., 1999) consisting of $(\mathrm{g} / \mathrm{L})$ : $\mathrm{K}_{2} \mathrm{HPO}_{4} \times 3 \mathrm{H}_{2} \mathrm{O} \quad 3.4 ; \quad \mathrm{KH}_{2} \mathrm{PO}_{4} \quad 1.3 ; \quad\left(\mathrm{NH}_{4}\right)_{2} \mathrm{SO}_{4} \quad 2.0$; $\mathrm{MgSO}_{4} \times 7 \mathrm{H}_{2} \mathrm{O} ; 0.2 \mathrm{CaCl}_{2} 0.02 ; \mathrm{FeSO}_{4} \times 7 \mathrm{H}_{2} \mathrm{O}$ 0.05; yeast extract 2.0 and $2 \mathrm{ml}$ trace element solution $\mathrm{SL}_{7}$ (Papanikolaou et al., 2000). The medium was supplemented with glycerol (50 g/L).

$H$. alvei was cultivated in the production medium consisting of $(\mathrm{g} / \mathrm{L}): \mathrm{K}_{2} \mathrm{HPO}_{4}$ 2.4; $\mathrm{KH}_{2} \mathrm{PO}_{4}$ 0.6; $\left(\mathrm{NH}_{4}\right)_{2} \mathrm{SO}_{4}$ 2; $\mathrm{MgSO}_{4} \times 7 \mathrm{H}_{2} \mathrm{O} \quad 0.4 ; \mathrm{CaCl}_{2} \times 2 \mathrm{H}_{2} \mathrm{O} \quad 0.1 ; \mathrm{CoCl}_{2} \times 2 \mathrm{H}_{2} \mathrm{O}$ 0.004 ; yeast extract 2; bactopeptone 2.5; meat extract 1.5. The medium was supplemented with glycerol $(50 \mathrm{~g} / \mathrm{L})$.

Batch fermentation procedures. A preculture of C. bifermentans strain was carried out in a $500 \mathrm{ml}$ flask containing $300 \mathrm{ml} \mathrm{PY}$ medium with glycerol at $37^{\circ} \mathrm{C}$ for $24 \mathrm{~h}$. It was inoculated into a 5L bioreactor (Sartorius Stedim, Germany) with 3L PY medium. According to Myszka and coworkers (Myszka et al., 2012), a blanket of a high-purity grade gas mixture of $5 \% \mathrm{O}_{2}$ and $95 \% \mathrm{CO}_{2}$ was maintained during cultivation. Gas flow rate was at up to $1.0 \mathrm{~L} / \mathrm{min}$, the stirrer speed varied between 200 and $500 \mathrm{rpm}$. The fermentation was run under microaerophilic conditions, at $30^{\circ} \mathrm{C}$ for 7 days.

A preculture of $C$. butyricum strain was carried out in a Hungate test tube in a culture chamber for anaerobes (Whitley MG500 by Scientific). After the adopted incubation time $\left(24 \mathrm{~h}, 32^{\circ} \mathrm{C}\right)$, the preinoculum was transferred, using a sterile syringe, to a bottle (Duran ${ }^{\circledR}$ ) integrated with a $5 \mathrm{~L}$ bioreactor (Sartorius Stedim, Germany). The bottle was placed in a water bath $\left(37^{\circ} \mathrm{C}\right)$ and incubated for $24 \mathrm{~h}$ to proliferate bacterial biomass. After incubation, the contents of the bottle were pumped to a bioreactor with a working capacity of $2 \mathrm{~L}$ with the use of a peristaltic pump. Fermentation was run for $72 \mathrm{~h}$ at $37^{\circ} \mathrm{C}, \mathrm{pH} 7.0$ was maintained by addition of $20 \%$ $\mathrm{NaOH}$. A blanket of a high-purity grade nitrogen gas was maintained during cultivation to ensure anaerobic conditions. Gas flow rate was at up to $1.0 \mathrm{~L} / \mathrm{min}$, the stirrer speed was constant at $70 \mathrm{rpm}$.

A preculture of $H$. alvei strain was carried out in a 250 $\mathrm{ml}$ flask containing $100 \mathrm{ml}$ of production medium with glycerol at $30^{\circ} \mathrm{C}$ for $24 \mathrm{~h}$. It was inoculated into 5L bioreactor (Sartorius Stedim, Germany) with 1L of production medium. The fermentation was carried out under controlled conditions: $\mathrm{pH} 7.0$, temperature $30^{\circ} \mathrm{C}$, and agitation rate $80 \mathrm{rpm}$ for $40 \mathrm{~h}$. No air or nitrogen sparging was used before and during the fermentation process.

Next the fermentations probes were taken out and analyzed by HPLC technique.

Analytical procedures. The ability of metabolite production by C. bifermentans KM371, C. butyricum DO14, and $H$. alvei AD27 was determined with a high liquid performance chromatography (HPLC) technique. The Hewlett Packard system consisting of an auto sampler and a pump, and a refractive index detector was used. The analysis was performed isocratically at a flow rate $0.6 \mathrm{~mL} / \mathrm{min}$. at $65^{\circ} \mathrm{C}$, on a Aminex HPX-87H300×7.8 column (Bio-Rad,USA). $0.5 \mathrm{mNH}_{2} \mathrm{SO}_{4}$ was also used as a mobile phase. Standards were applied to identify peaks in chromatograms, and peak areas were measured to determine the samples' concentration (ChemStation, Agilent, USA).

\section{RESULTS}

In the earlier research carried out in the Department of Biotechnology and Food Microbiology (Poznan University of Life Sciences) several new strains capable of 1,3-PD production, from the species of $C$. bifermentans, C. butyricum, and $H$. alvei among others, were obtained (Myszka et al., 2012; Orczyk \& SzymanowskaPowałowska, 2012). Because C. bifermentans and $H$. alvei have never been characterized as a 1,3-PD producers, we decided to investigate their glycerol metabolic pathway and compare it with C. butyricum pathway, a typical 1,3PD producer.

As a result, it was found out that all three investigated strains were capable of 1,3-PD, lactic acid, acetic acid, and succinic acid, acid production. Additionally, C. butyricum DO14 and $H$. alvei AD27 synthetized ethanol, $C$. bifermentans and $C$. butyricum synthetized fumaric acid, and only $C$. butyricum produced butyric acid. The hypothetic pathways of glycerol in the above mentioned strains are presented in Fig. 1.

Despite the fact that the metabolite profiles of investigated bacteria were similar, the quantitative ratios between individual products were different in all strains. The highest level of 1,3-PD was synthetized by $C$. butyricum strain. C. bifermentans produced the highest amount of organic acids: lactic, fumaric, acetic, and succinic. Butyric acid was produced only by one strain $-C$. butyricum (Fig. 2).

Additionally, the percentage of individual metabolites in all synthetized products, the metabolite yields and productivity are presented in Table 1 . In case of all three investigated strains, 1,3-PD was the main metabolite: in C. butyricum DO14 it constituted $60.11 \%$ of all produced metabolites, in $H$. alvei AD27 - 55.39\%, and 32.69\% in C. bifermentans KM371. The highest $\mathrm{P}_{\mathrm{a}}$ for 1,3-PD was obtained for C. butyricum — the maximum level of this metabolite was obtained after $72 \mathrm{~h}$ of cultivation. Significantly, this strain was able to synthetize about 2.5 times more 1,3-PD than C. bifermentans and ca. 2 times more than $H$. alvei, which was cultivated for the shortest time. Quantitatively, the second metabolite in C. bifermentans was lactic acid $(27.37 \%$ of all metabolites), in C. butyricum - butyric acid $(14.55 \%)$, and in $H$. alvei — acetic acid $(19.87 \%)$.

Also, the level of glycerol utilization and its kinetics were different in all investigated strains (Fig. 3). The end of the culture was regarded as the moment when the level of metabolites has no longer increasing. Thus, this time is different for all three strains. The most effective utilization of glycerol was observed for C. butyricum strain. During 72 hours of cultivation total glycerol was consumed. Despite the fact that the utilization of glycerol (and metabolite production) in C. bifermentans required 168 hours of cultivation, the level of its utilization was high $-94.32 \%$. H. alvei consumed less glycerol $(56.48 \%)$, however the maximum amount of metabolites was obtained 3.5 times faster, already after 48 hours of cultivation; additionally, raw material was utilized by this strain more intensively than by $C$. bifermentans.

These preliminary studies of metabolism of $C$. bifermentans and $H$. alvei demonstrate that these strains are capable of 1,3-PD production from glycerol. Because 

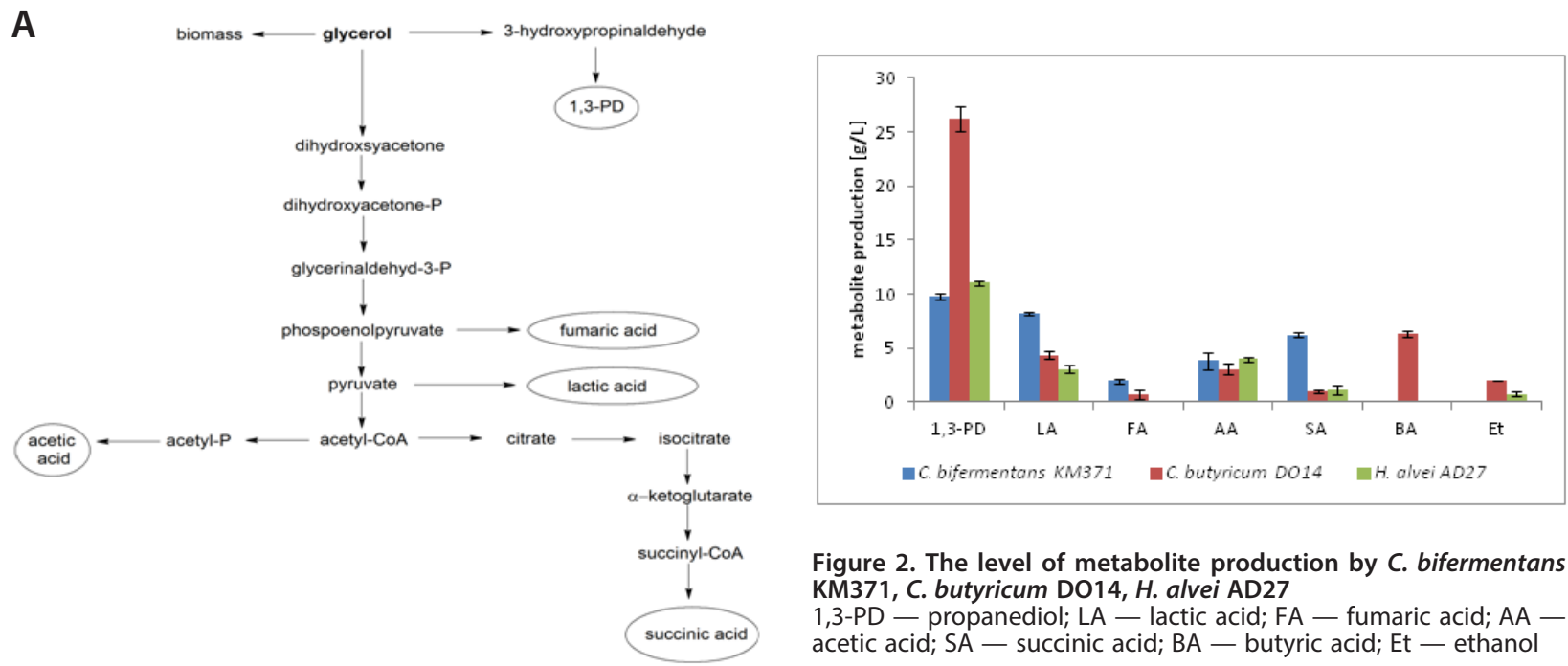

Figure 2. The level of metabolite production by C. bifermentans KM371, C. butyricum DO14, H. alvei AD27

1,3-PD - propanediol; LA - lactic acid; FA - fumaric acid; AA acetic acid; SA — succinic acid; BA — butyric acid; Et — ethanol
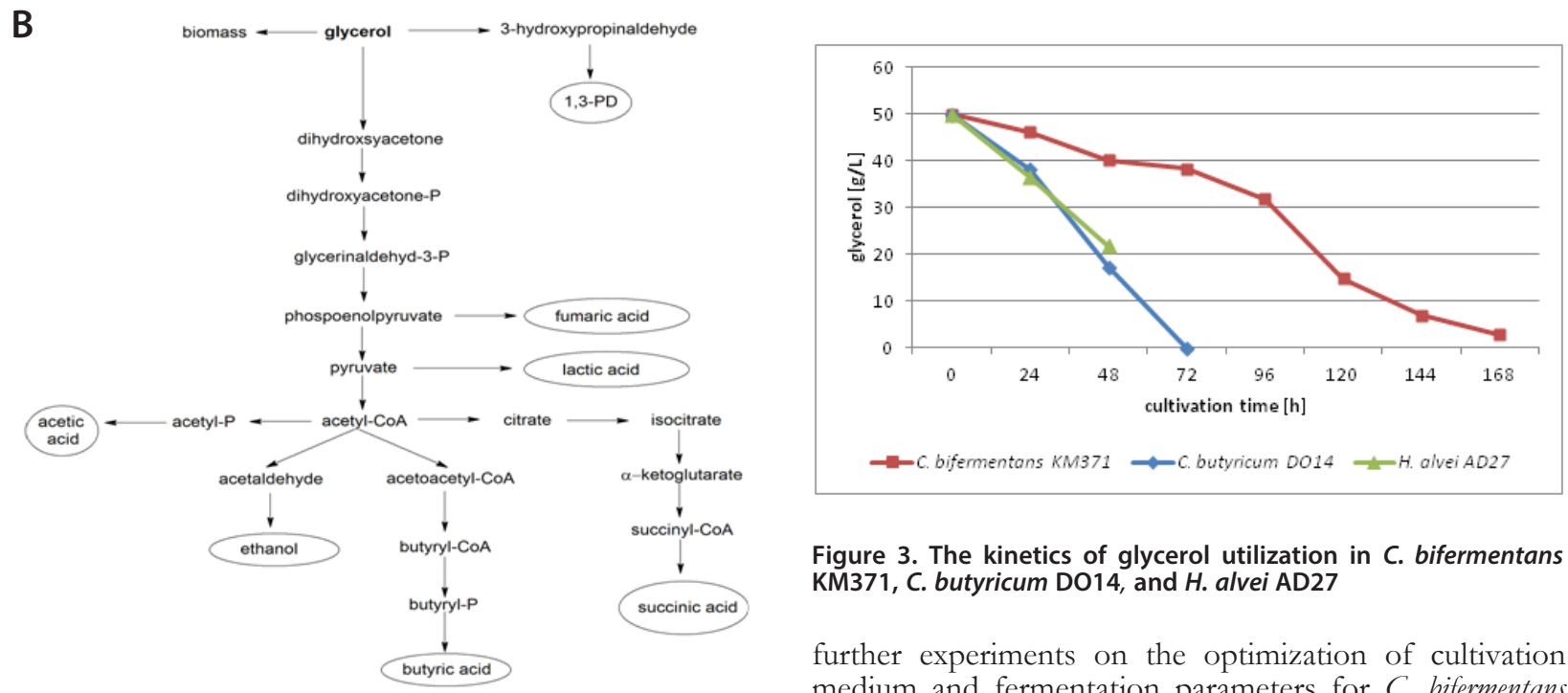

Figure 3. The kinetics of glycerol utilization in C. bifermentans KM371, C. butyricum DO14, and H. alvei AD27

further experiments on the optimization of cultivation medium and fermentation parameters for C. bifermentans and $H$. alvei should be done.

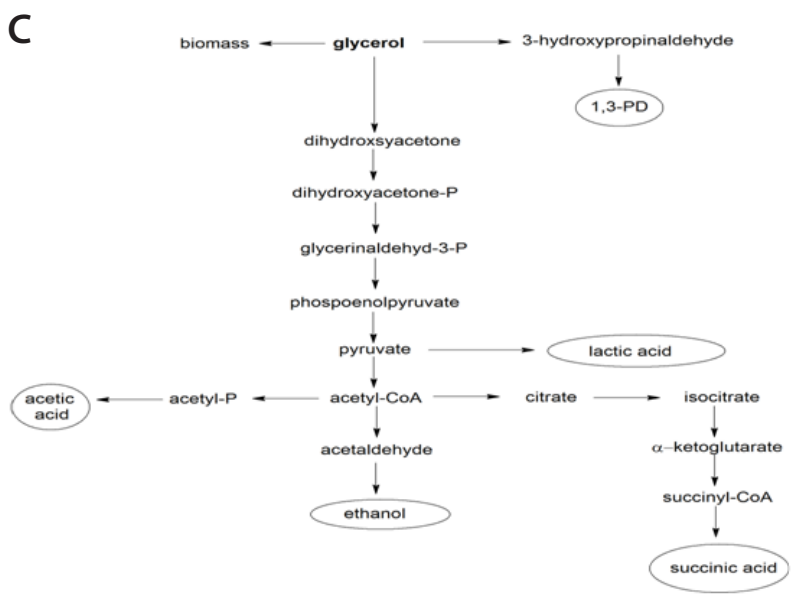

\section{DISCUSSION}

The natural environment is a rich source of industrially useful microorganisms. Isolating such bacteria and developing methods of application in a number of industry branches is an important step in substituting chemical synthesis by microbiological processes. Chemical synthesis produces significant quantities of by-products, contaminating the natural environment; moreover, it has a low specificity. On the other hand, biotechnological methods circumvent these problems (Kaeberlein et al., 2002; Nicol et al., 2012).

In our earlier experiments we obtained strains capable of 1,3-PD production from glycerol. Some of these strains have not been described as yet by other scientist as 1,3-PD producers, such as C. bifermentans and $H$.

Figure 1. Hypothetic glycerol pathways in investigated strains: (A) C. bifermentans KM371, (B) C. butyricum DO14, (C) H. alvei AD27

alvei. C. butyricum strains that are known to be able to synthesize 1,3-PD, were also obtained. The metabolism of $C$. bifermentans and $H$. alvei has not been investigated in detail yet, thus we decided to compare it with $C$. butyricum.

In the literature there is some incoherent information about the metabolism of $C$. bifermentans. For example, Dezfulian and coworkers (Dezfulian et al., 1994) isolat- 
Table 1 Basic kinetic parameters of fermentation in investigated strains

\begin{tabular}{|c|c|c|c|c|}
\hline Strain & Product & $\%$ & $Y_{p / s}$ & $P_{a}$ \\
\hline \multirow{7}{*}{ C. bifermentans } & 1,3-PD & 32.69 & 0.20 & 0.06 \\
\hline & LA & 27.37 & 0.16 & 0.05 \\
\hline & FA & 6.48 & 0.04 & 0.01 \\
\hline & AA & 12.73 & 0.08 & 0.02 \\
\hline & SA & 20.72 & 0.12 & 0.04 \\
\hline & BA & nd & nd & nd \\
\hline & Et & nd & nd & nd \\
\hline \multirow{7}{*}{ C. butyricum } & $1,3-P D$ & 60.11 & 0.52 & 0.36 \\
\hline & LA & 9.97 & 0.09 & 0.06 \\
\hline & FA & 1.67 & 0.01 & 0.01 \\
\hline & $A A$ & 6.99 & 0.06 & 0.04 \\
\hline & SA & 2.20 & 0.02 & 0.01 \\
\hline & BA & 14.55 & 0.13 & 0.09 \\
\hline & Et & 4.51 & 0.04 & 0.03 \\
\hline \multirow{7}{*}{ H. alvei } & 1,3-PD & 55.39 & 0.22 & 0.23 \\
\hline & LA & 15.40 & 0.06 & 0.06 \\
\hline & FA & nd & nd & nd \\
\hline & $A A$ & 19.87 & 0.08 & 0.08 \\
\hline & SA & 5.52 & 0.02 & 0.02 \\
\hline & BA & nd & nd & nd \\
\hline & Et & 3.81 & 0.02 & 0.02 \\
\hline
\end{tabular}

1,3-PD — propanediol; LA — lactic acid; FA — fumaric acid; AA — acetic acid; SA — succinic acid; BA — butyric acid; Et — ethanol; \% — the per-

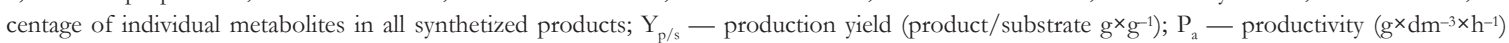

ed 20 strains of C. bifermentans from samples from desert tortoise Gopherus agassizii in California. It was found that none of them were capable of glycerol utilization. However, earlier studies carried out by McCoy and McClung (Mccoy \& Mcclung, 1936) and Brooks and Epps (Brooks \& Epps, 1958) indicated that C. bifermentans are able to carry out glycerol fermentation. In the work presented here this ability was also proven. Because there is no literature data about the glycerol pathway in $C$. bifermentans strains, we decided to investigate it. As a result, it was found that by-products from glycerol utilization such as organic acids (such as lactic, acetic, succinic, and formic acid) are synthetized. Additionally, the level of lactic acid synthesis is high. This ability has not been presented yet by other scientists. In the literature there is more information about amino acid utilization by $C$. bifermentans and volatile acid synthesis (Mead, 1971; Elsden et al., 1976; Elsden \& Hilton, 1978) and utilization of glucose into ethanol and acetic acid (Turton et al., 1982).

The ability of $H$. alvei for glycerol utilization has already been described (Homann et al., 1990; Rodriguez et al., 1998; McBee \& Schauer, 2006; Hao et al., 2008; Rossi et al., 2012). However, the capability of 1,3-PD production by $H$. alvei has been not investigated yet by any other scientists. Significantly, the metabolic pathway of glycerol in this strain has not been presented. During the course of this work it was found that a by-products from glycerol to 1,3-PD utilization include organic acids such as lactic, acetic, and succinic and ethanol.

C. butyricum is well-known as a 1,3-PD producer from glycerol (Biebl et al., 1998; Hao et al., 2008; Biebl et al., 1992; Kubiak et al., 2012; Wilkens et al.,
2012; Samul et al., 2013; Ringel et al., 2012). According to the literature data, $C$. butyricum utilizes glycerol to 1,3-PD and by-products: ethanol and lactic, butyric and acetic acids (Zeng \& Biebl, 2002). A new strain from this species was obtained and its glycerol metabolic pathway has been presented in this work. It is also able to produce ethanol and organic acids: lactic, acetic, fumaric, succinic and butyric acid, unlike $C$. bifermentans and $H$. alvei. It occurred that the metabolic pathway of the newly isolated $C$. butyricum DO14 strain was slightly different than in the strain described by Zeng and Biebl (Zeng \& Biebl, 2002) it produces also fumaric and succinic acids.

These results indicate that a natural environment is a good source of bacterial strains with a huge industrial potential. Moreover, these strains show significant biodiversity. The number of strain isolation studies is still on the increase. Scientists are screening the natural environment for new strains capable of glycerol conversion to usable metabolites, including 1,3-PD (Ringel et al., 2012; Jungermann et al., 1973; Hiremath et al., 2011; Sattayasamitsathit et al., 2011; Gelder et al., 2012; Hong et al., 2013). As a result, new strains were obtained, among them: Trichococcus flocculiformis (Gelder et al., 2012), Klebsiella pneumoniae and Pantoea agglomerans (Rossi et al., 2012), C. butyricum (Ringel et al., 2012). However, no research focused on the isolation of bacteria from environmental samples of unknown capacity for the synthesis of 1,3-PD has been conducted yet. In the present work, two strains ( $C$. bifermentans and $H$. alver) with so far unknown capacity for the synthesis of 1,3-PD are described. 


\section{Acknowledgements}

This paper was prepared within the framework of project PO IG 01.01.02-00-074/09 co-funded by The European Union from The European Regional Development Fund within the framework of the Innovative Economy Operational Programme 2007-2013.

\section{REFERENCES}

Bergey DH, Harrison FC, Breed RS, Hammer BW, Huntoon FM (1984) Bergey's Manual of Determinative Bacteriology, pp 436-455. The Williams \& Wilkins Co, Baltimore.

Biebl H, Marten S, Hippe H, Deckwer WD (1992) Glycerol conversion to 1,3-propanediol by newly isolated clostridia. Appl Microbiol Biotechnol 36: 592-597.

Biebl H, Spröer C (2002) Taxonomy of the glycerol fermenting Clostridia and description of Clostridium diolis sp. nov. Syst Appl Microbiol 24: 491-497.

Biebl H, Zeng AP, Menzel K, Deckwer WD (1998) Fermentation of glycerol to 1,3-propanediol and 2,3-butanediol by Klebsiella pneumonia. Appl Microbiol Biot 50: 24-29.

Brenner DJ, Krieg NR, Staley JR (2005) Bergey's Manual of Systematic Bacteriology: The Proteobacteria: Part B The Gammaproteobacteria. 2nd edn, pp 587-850.

Brooks E, Epps HBG (1958) Taxonomic studies of the genus Clostridium: Clostridium bifermentans and Clostridium sordelli. J Gen Microbiol 21: 144-155.

Dabrock B, Bahl H, Gottschalk G (1992) Parameters affecting solvent production by Clostridium pasteurianum. Appl Microbiol Biotechnol 58: 1233-1239.

Dezfulian M, Quintana A, Solleymani B, Morafka D (1994) Physiological characteristics of Clostridium bifermentans selectively isolated from California desert tortoise. Folia Microbiol 39: 496-500.

Elsden SR, Hilton MG (1978) Volatile acid production from threonine, valine, leucine and isoleucine by Clostridia. Arch Microbiol 117: 165-172.

Elsden SR, Hilton MG, Waller JM (1976) The end products of the metabolism of aromatic amino acids by Clostridia. Arch Microbiol 107: 283-288.

Gelder AH, Aydin R, Alves MM, Stams AJM (2012) 1,3-propanediol production from glycerol by a newly isolated Trichococcus strain. $\mathrm{Mi}$ crobial Biotechnol 5: 573-578.

Hao J, Lin R, Zheng Z, Liu H, Liu D (2008) Isolation and characterization of microorganisms able to produce 1,3-propanediol under aerobic conditions. World J Microb Biot 24: 1731-1740.

Himmi EL, Bories A, Barbirato F (1999) Nutrient requirements for glycerol conversion to 1,3-propanediol by Clostridium butyricum. Bioresour Technol 67: 123-128.

Hiremath A, Kannabiran M, Rangaswamy V (2011) 1,3-Propanediol production from crude glycerol from jatropha biodiesel process. New Biotechnol 28: 19-23.

Homann T, Tag C, Biebl H, Deckwer WD, Schink B (1990) Fermentation of glycerol to 1,3-propanediol by Klebsiella and Citrobacter strains. App Microbiol Bio 33: 121-126.

Hong E, Yoon S, Kim J, Kim E, Kim D, Rhie S, Ryu YW (2013) Isolation of microorganisms able to produce 1,3-propanediol and optimization of medium constituents for Klebsiella pneumoniae AJ4. Bioprocess Biosyst Eng 36: 835-843.

Jones DT, Woods DR (1986) Acetone-butanol fermentation revisited. Microbiol Rev 50(4): 481-524.

Jungermann K, Thauer RK, Leimenstoll G, Decker K (1973) Function of reduced pyridine nucleotide-ferredoxin oxidoreductases in saccharolytic clostridia. Biochimica et Biophysica Acta 305: 268-280.

Kaeberlein T, Lewis K, Epstein SS (2002) Isolating "uncultivable" microorganisms in pure culture in a simulated natural environment. Science 296: 1127-1129.

Khanal SM, Chen WH, Sung S (2004) Biological hydrogen production: effects of $\mathrm{pH}$ and intermediate products. Int J HN Energy 29: 1123-1131.
Kubiak P, Leja K, Myszka K, Celińska E, Spychała M, SzymanowskaPowałowska D, Czaczyk K, Grajek W (2012) Physiological predisposition of various Clostridium species to synthetize 1,3-propanediol from glycerol. Process Biochem 47: 1308-1319.

Leja K, Myszka K, Kubiak P, Wojciechowska J, Olejnik-Schmidt AK, Czaczyk K, Grajek W (2011) Isolation and identification of Clostridium spp. from natural samples that performs effective conversion of glycerol to 1,3-propanediol. Acta Sci Pol, Biotechnologia 10: 25-34.

Levin BD, Islam R, Cicek N, Sparling R (2006) Hydrogen production by Clostridium thermocellum 27405 from cellulosic biomass substrates. Int J HN Energy 31: 1496-1503.

McBee ME, Schauer DB (2006) The Genus Hafnia. Prokaryotes 6: 215 218.

Mccoy E, Mcclung S (1936) Studies on anaerobic bacteria. Antigenic relations of Clostridium bifermentans and Clostridium centrosporogenes. J Bacteriol 31: 557.

Mead GC (1971) The amino acid-fermenting Clostridia. J Gen Microbiol 67: 47-56.

Myszka K, Leja K, Olejnik-Schmidt AK, Czaczyk K (2012) Isolation process of industrially useful Clostridium bifermentans from natural samples. J Biosc Bioeng 113: 631-633.

Nachman S, Kaul A, Li KI, Slim MS, Filippo JA, Horn KV (1989) Liver abscess caused by Clostridium bifermentans following blunt abdominal trauma. J Clin Microbiol 27: 1137-1138.

Nicol RW, Marchand K, Lubitz WD (2012) Bioconversion by crude glycerol by fungi. Appl Microbiol Biotechnol 93: 1865-1875.

Orczyk D, Szymanowska-Powałowska D (2012) Isolation of bacteria of the genus Clostridium able to conversion of glycerol to 1,3-propanediol and optimization of medium. Engine Science and Technol 2: 44-59 (in Polish).

Papanikolaou S, Ruiz-Sanchez P, Pariset B, Blanchard F, Fick M (2000) High production of 1,3-propanediol from industrial glycerol by a newly isolated Clostridium butyricum strain. I Biotechnol 77: 191-208.

Petitdemange E, Dürr C, Andaloussi SA, Raval G (1995) Fermentation of raw glycerol to 1,3-propanediol by new strains of Clostridium butyricum. I Ind Microbiol 15: 498-502.

Ringel AK, Wilkens E, Hortig D, Willke T, Vorlop KD (2012) An improved screening method for microorganisms able to convert crude glycerol to 1,3-propanediol and to tolerate high product concentrations. Appl Microbiol Biotechnol 93: 1049-1056.

Rodriguez LA, Gallardo CS, Acosta F, Nieto TP, Acosta B, Real F (1998) Complete genome analysis of the mandarin fish infectious spleen and kidney necrosis iridovirus. J Fish Disease 21: 365-369.

Rossi DM, Da Costa JB, De Souza EA, Peralba MCR, Ayub MAZ (2012) Bioconversion of residual glycerol from biodiesel synthesis into 1,3-propanediol and ethanol by isolated bacteria from environmental consortia. Renew Energ 39: 223-227.

Samul D, Worsztynowicz P, Leja K, Grajek W (2013) Beneficial and harmful roles of bacteria from the Clostridium genus. Acta Biochm Pol 60: $515-521$

Sattayasamitsathit S, Prasertsan P, Methacanon P (2011) Statistical optimization for simultaneous production of 1,3-propanediol and 2,3-butanediol using crude glycerol by newly bacterial isolate. Proc Biochem 46: 608-614.

Turton LJ, Drucker DB, Ganguli LA (1982) Effect of glucose concentration in the growth medium upon neutral and acidic fermentation end-products of Clostridium bifermentans, Clostridium sporogenes and Peptostreptococcus anaerobius. J Med Microbiol 16: 61-67.

Wang CC, Chang CW, Chu CP, Lee DJ, Chang BV, Liao CS (2003) Producing hydrogen from wastewater sludge by Clostridium bifermentans. J Biotechnol 102: 83-92.

Wilkens E, Ringel AK, Hortig D, Willke T, Vorlop KD (2012) Highlevel production of 1,3-propanediol from crude glycerol by Clostridium butyricum AKR102a. Appl Microbiol Biot 93: 1057-1063.

Wu Z, Yang SH (2003) Extractive fermentation for butyric acid production from glucose by Clostridium tyrobutyricum. Biot Bioengin 82: 93-102.

Zeng AP, Biebl H (2002) Bulk-Chemicals from Biotechnology: the case of microbial production of 1,3-propanediol and the new trends (in) Tools and applications of biochemical engineering science, red. Schügerl and A.P. Zeng, Adv Biochem Eng Biotechnol 74: 237-257. 